\title{
Anatomy eats strategy for breakfast
}

\author{
Joanna Chikwe, MD
}

\author{
From the Department of Cardiovascular Surgery, Icahn School of Medicine at Mount Sinai, New York, NY; and \\ the Department of Surgery, The State University of New York, Stony Brook, NY. \\ Disclosures: Author has received speaker honoraria from Edwards Lifesciences. \\ Received for publication Jan 29, 2018; accepted for publication Jan 31, 2018. \\ Address for reprints: Joanna Chikwe, MD, Department of Cardiovascular Surgery, Icahn School of Medicine at \\ Mount Sinai, 1190 Fifth Ave, New York, NY 10029 (E-mail: Joanna.Chikwe@mountsinai.org). \\ J Thorac Cardiovasc Surg 2018;156:247-8 \\ $0022-5223 / \$ 36.00$ \\ Copyright (C) 2018 by The American Association for Thoracic Surgery \\ https://doi.org/10.1016/j.jtcvs.2018.01.061
}

In their case report in this issue of the Journal, Kim and colleagues ${ }^{1}$ report trading a benign lipoma for a mechanical mitral prosthesis in a symptom-free 42 -year-old patient by excising a functionally normal mitral valve to facilitate resection of a papillary muscle mass. Their video is worth watching for the sequence of decisions triggered by difficulty in exposing the subvalvular apparatus, leading Kim and colleagues ${ }^{1}$ to detach the anterior mitral leaflet from the annulus partially, eventually excising the entire mitral valve.

Although cardiac magnetic resonance imaging differentiates lipomas from malignant tumors, the role of surveillance in this symptom-free patient is unclear, because the natural history of intracardiac lipomas is unknown. ${ }^{2}$ What is known are the long-term outcomes of mitral valve replacement. In adults younger than 50 years, mechanical prostheses are associated with a survival benefit relative to bioprostheses_but at a high price: in addition to the lifelong requirement for anticoagulation, at 15 years, the mortality is $20 \%$, and the risks of stroke, major bleeding, and mitral reoperation are $10 \%, 12 \%$, and $6 \%$ respectively. ${ }^{3}$ The third option was to mitigate these risks by preserving the mitral valve-but how?

1. Exposure of the subvalvular apparatus is readily obtained by traction sutures around the main chordae of the anterior leaflet or a curved retractor under it. ${ }^{4}$ The lipoma is clearly visible beneath the anterior leaflet $5 \mathrm{sec}$ onds into the video, and these standard maneuvers might have allowed the team to enucleate it without needing to resect any leaflet tissue.

2. Alternatively, detaching the fibrous head from the body of the involved papillary muscle would achieve 2 ends. First, this mobilizes the leaflet enough to expose the whole papillary muscle, facilitating resection of the mass; second, it provides a straightforward option for reimplanting the papillary muscle fibrous head and attached chordae onto an adjacent papillary muscle.

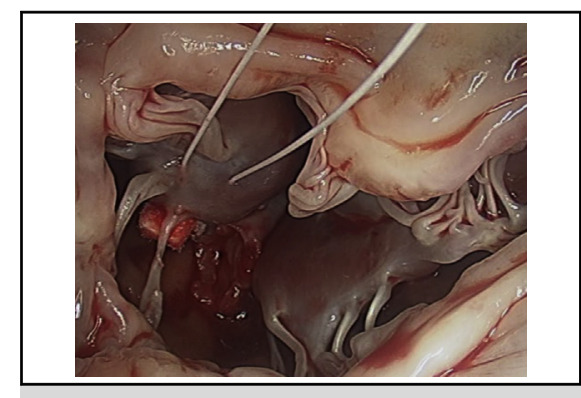

Access to the subvalvular apparatus allows effective repair of papillary muscle pathology.

\section{Central Message}

Safe and effective repair of single papillary muscle pathology can be achieved with a few simple techniques.

See Article page 244 .
This strategy is useful for repairing ischemic papillary muscle rupture (Figure 1), has been modified for extended septal myectomy, ${ }^{5}$ and could have allowed Kim and colleagues ${ }^{1}$ to resect the entire papillary muscle and preserve the mitral valve.

3. Kim and colleagues ${ }^{1}$ elected to detach the anterior leaflet from the annulus (at around 17 seconds on the video), nicely exposing the lipoma and subvalvular apparatus. Reattaching the anterior mitral valve leaflet to the annulus with a continuous running 4/0 Prolene (Ethicon US, LLC, Somerville, NJ) suture, either patch augmented or buttressed with pericardium and supported by a remodeling annuloplasty ring, offers a technically simple and durable approach to restoring mitral valve competence. $^{4}$

4. These simple surgical techniques are greatly facilitated by endoscopic instruments and an endoscopic camera.

In summary, this unusual case of Kim and colleagues $^{1}$ highlights a common theme. A safe and effective mitral repair was desirable and probably feasible-but challenging exposure of pathology that was more complex than expected drove the decision to replace the valve. In the left atrium, anatomy eats strategy for breakfast. 


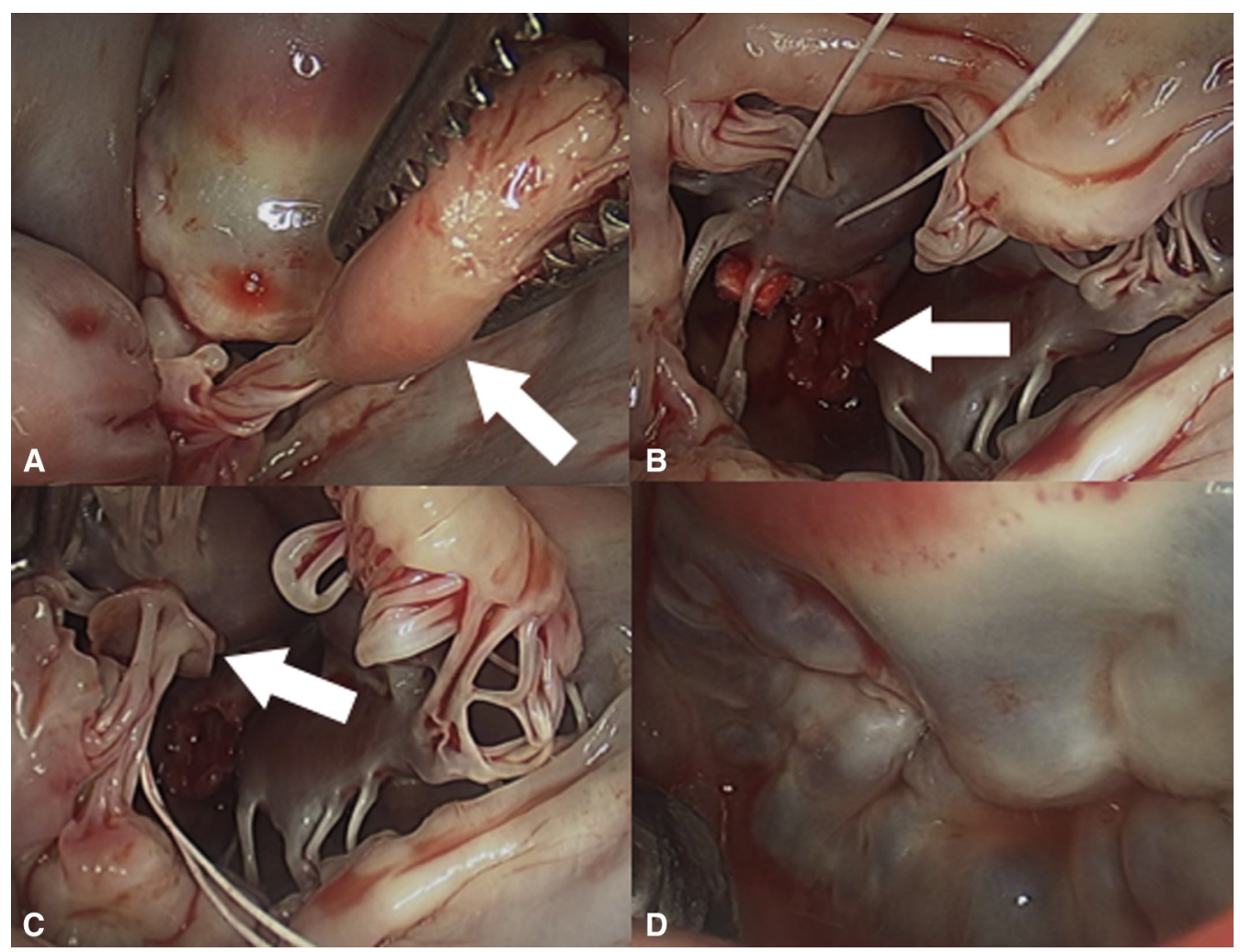

FIGURE 1. Repair of ischemic papillary muscle rupture. A, Ruptured body of the papillary muscles in forceps (arrow) with intact chordae attached to P1. B, Pledgeted 4/0 GORE-TEX (W.L. Gore and Associates, Flagstaff, Ariz) passed through the fibrous head of the intact anterolateral papillary muscle, adjacent to the ischemic stump of the ruptured papillary muscle (arrow). C, Fibrous head (arrow) of the ruptured papillary muscle with chordae to P1 preserved, reimplanted onto the fibrous head of the anterolateral papillary muscle. D, Competent saline solution test.

\section{References}

1. Kim YS, Lee KH, Choi SJ, Baek WK. Cardiac lipoma arising from left ventricular papillary muscle: resect or not? J Thorac Cardiovasc Surg. 2018;156:244-6.

2. D'Souza J, Shah R, Abass A, Burt JR, Goud A, Dahagam C. Invasive cardiac lipoma: a case report and review of the literature. BMC Cardiovascular Disord. 2017;17:28.

3. Schnittman S, Itagaki S, Toyoda N, Adams DH, Egorova NE, Chikwe J. Survival and long-term outcomes after mitral valve replacement in patients aged 18-50 years. J Thorac Cardiovasc Surg. 2018;155: 96-102.e11.

4. Carpentier A, Adams DH, Filsoufi F. Carpentier's Reconstructive Valve Surgery. Philadelphia: Saunders; 2010.

5. Meier S, Noack T, Mohr FW, Seeburger J, Passage J. Transmitral myectomy and how to deal with systolic anterior motion (SAM) in hypertrophic obstructive cardiomyopathy. Ann Cardiothorac Surg. 2017;6:416-8. 